\title{
FRONTEIRAS IMAGINADAS: EXPERIÊNCIAS EDUCATIVAS E CONSTRUÇÃO DAS DISPOSIÇÕES QUANTO AO FUTURO POR JOVENS DOS GRUPOS POPULARES E MÉDIOS*
}

\author{
Sueli Presta \\ Ana Maria F. Almeida ${ }^{* * *}$
}

\begin{abstract}
RESUMO: O artigo discute os resultados de uma pesquisa que procurou focalizar os processos pelos quais adolescentes de diferentes grupos sociais constroem disposições quanto ao futuro em relação à escola e ao trabalho. A partir de entrevistas com 14 jovens e suas famílias foi possível mostrar que as disposições quanto ao futuro são tributárias, por um lado, do sentido da trajetória social do grupo familiar (ascendente ou descendente) e, por outro, da estrutura dos patrimônios, material e simbólico, de que dispõem essas famílias, gerando, ao final, um ajustamento claro entre disposiçóes e chances de torná-las realidade. Essa congruência só é ameaçada pelo veredito escolar que pode impor percepçôes diferentes de futuro daquelas construídas na relação com a família. As implicações desses resultados são discutidas ao final.
\end{abstract}

Palavras-chave: Jovens. Disposições quanto ao futuro. Desigualdades sociais.

* Esse artigo apresenta resultados das pesquisas das autoras apoiadas pelo CNPq.

** Mestre em Educação e professora da Rede Municipal de Ensino de Campinas. E-mail: paulapresta@interall.com.br

*** Doutora em Educação, professora da Faculdade de Educação da Universidade Estadual de Campinas (UNICAMP) e pesquisadora do Grupo de Estudos sobre Instituição Escolar e Organizações Familiares (Focus) na mesma Universidade. E-mail: aalmeida@unicamp.br 
Fronteiras imaginadas: experiências educativas e construção das disposições...

IMAGINED FRONTIERS: EDUCATIONAL EXPERIENCES AND THE CONSTRUCTION OF PLANS FOR THE FUTURE BY A GROUP OF LOWERAND MIDDLE-CLASS YOUNGSTERS

ABSTRACT: This article is about the results of a study focusing on processes through which adolescents from different social groups build their plans for the future in terms of schools and jobs. From interviews with 14 youngsters and their families, it was possible to make it clear that these plans for the future are closely related to their families' (ascending or descending) social history, on the one hand, and on the other hand, to the structure of assets these families have, and that all this results in a clear adjustment between the plans and the chances to make them come true. This convergence is only threatened by schools' verdicts, which may impose different perceptions about the future than the ones built in family relations. The implications of these results will be discussed at the end of the text.

Key words: Youngsters. Plans for the future. Social inequality.

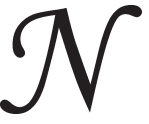

ão é possível interrogar sobre a construção de fronteiras sociais no Brasil contemporâneo sem se confrontar com a alta desigualdade de rendas e sua persistência no tempo. Índices, como o de Gini, relatórios de agências transnacionais, como o Human Development Report das Naçôes Unidas, assim como uma enxurrada de artigos acadêmicos convergem para mostrar que o Brasil vem convivendo com as mais altas taxas de desigualdade do planeta há pelo menos quatro décadas.

Em tal quadro, problematizar a relação entre experiências educativas e construção de fronteiras sociais pode ser pensado como uma tentativa de ir além dos números frios que apontam o abismo que separa os modos de vida dos diferentes grupos sociais, para focalizar os processos que, fundando uma determinada situação, parecem justificar e talvez explicar a sua ocorrência e recorrência no tempo. A pesquisa que está na origem deste artigo foi, assim, pensada como uma incursão na dinâmica da desigualdade brasileira.

Pensar em termos de "dinâmica da desigualdade" implica alguns desafios. Como aponta Reis (2000), embora a pobreza e a desigualdade sejam temas tradicionais das Ciências Sociais, os dois termos são raramente tratados de forma articulada no Brasil. Por um lado, a desigualdade é um objeto de estudo quase exclusivo dos economistas, que abordam a questão 
preocupados, em geral, com a formulação de políticas públicas. ${ }^{1}$ Por outro, os estudos desenvolvidos por antropólogos, sociólogos e cientistas sociais que focalizam os grupos desprivilegiados, embora tenham produzido um acúmulo significativo de conhecimento sobre os modos de vida desses grupos, raramente examinam os processos pelos quais tais grupos são preteridos ou totalmente excluídos das arenas de distribuição das riquezas coletivamente produzidas na nossa sociedade.

A pesquisa que está na origem deste artigo procurou enfrentar essa questão por meio da articulação entre, por um lado, a noção de "fronteira social" e, por outro, a noção de "fronteira simbólica". Tendo sempre por referência uma formação social determinada, a primeira pretende dar conta da repartição desigual das riquezas coletivamente produzidas (Lamont \& Molnár, 2002), enquanto a segunda diz respeito às interpretações coletivas de que são objeto tais desigualdades da repartição (idem, ibid.). A discussão apresentada aqui está centrada nessa segunda questão. Nos dois casos, a noção de "fronteira", tomada no sentido em que é discutida por autores como Tilly (2004) e Collins (2000), por exemplo, explicita a intenção de tratar as separações entre os grupos como algo mais dinâmico e permeável do que a noção de desigualdade normalmente o faz, chamando a atenção para os processos de dominação e exploração que as constroem.

No nosso caso, estamos interessadas em discutir a gênese dessas fronteiras simbólicas que fundam, para os próprios indivíduos, o território dos possíveis e dos impossíveis, do desejado e do indesejado e assim por diante. Procurando ultrapassar as explicações que compreendem as fronteiras simbólicas como produtos ou expressão mais ou menos espontâneos e mais ou menos automáticos de uma "cultura", tentamos problematizar as condições que tornam possível a própria existência desta "cultura”. Para isso, construímos nossos instrumentos de produção de dados (observações, entrevistas aprofundadas e às vezes repetidas, estudo de documentos e estatísticas oficiais) com o objetivo de examinar os constrangimentos e possibilidades que definem as condições objetivas de existência dos indivíduos focalizados aqui.

A noção de fronteira simbólica foi operacionalizada na pesquisa por meio do exame das disposições quanto ao futuro em adolescentes de grupos populares e médios. Procuramos captar, assim, tanto os desejos quanto as negaçóes que aparecessem, de forma espontânea ou estimulada, no discurso dos jovens em foco. 
Fronteiras imaginadas: experiências educativas e construção das disposições...

Interessadas primordialmente nos processos de construção das fronteiras simbólicas nas novas gerações, utilizamos a noção de "experiências educativas" para articular as condiçôes de existência ao trabalho socializador efetivamente realizado por famílias, escolas e outras instituições.

Os dados que trabalharemos nesse artigo foram obtidos ao longo de uma pesquisa coletiva que, a partir de 2005, mobilizou uma dezena de pesquisadores e que ainda se encontra em andamento. $\mathrm{O}$ trabalho de campo de tipo etnográfico foi realizado numa cidade de porte médio do interior de São Paulo, numa região geográfica particular formada por três bairros contíguos localizados nas vizinhanças de duas grandes universidades, uma pública e outra privada. ${ }^{2} \mathrm{O}$ primeiro, denominado aqui Céu $A z u l$, reúne famílias de baixa renda (diferentes frações dos grupos populares e classe média inferior). As mulheres são, em maioria absoluta, empregadas domésticas mensalistas ou diaristas. Algumas estão empregadas nas empresas da região, desempenhando em geral tarefas de limpeza. Os homens, por sua vez, são em maioria mãode-obra autônoma na construção civil (pedreiros, pintores de parede, caibreiros, serralheiros) ou jardineiros nos bairros de classe média das proximidades. É importante notar que se trata aqui de um bairro popular que apresenta ruas asfaltadas e todas as casas são servidas de água encanada e esgoto. Os terrenos são legalizados e são lugar de moradia de pelo menos dois núcleos familiares, em geral pais e filhos, mas, às vezes, dois irmãos ou irmãs. As casas são de alvenaria, resultado de autoconstrução, a maioria apresentando aquele ar inacabado decorrente da falta de reboco e pintura tão comum nos bairros populares das grandes cidades brasileiras, embora muros e portôes altos disfarcem em boa medida essa situação. O segundo bairro, denominado Parque da Universidade, é definitivamente de classe média, reunindo famílias de professores das universidades, engenheiros ou outros profissionais liberais. Para além daqueles empregados nas universidades, os adultos dessas famílias trabalham nas indústrias das vizinhanças ou tem seus escritórios, consultórios e clínicas nas proximidades. Uma minoria não negligenciável trabalha em empresas ou universidades localizadas em outras cidades mais ou menos próximas, podendo viajar mais de 200 quilômetros entre ida e volta todos os dias ou algumas vezes por semana. Essa situação é facilitada pelo fato de que os bairros em questão localizam-se nas proximidades de um importante entroncamento rodoviário do estado de São Paulo, sendo servidos por estradas de boa qualidade. Um êxodo 
importante das famílias de maiores posses econômicas aconteceu ao longo dos anos de 1990, na seqüência da construção de vários condomínios nas proximidades. As casas antes habitadas por essas famílias no bairro estão sendo ocupadas por moradias estudantis. Por fim, o terceiro bairro focalizado, denominado Araras, é mais misturado, agregando famílias dos grupos populares do tipo descrito acima e outras ainda mais pobres, mas encontra-se em vias de gentrificação, tendo recebido na última década um contingente importante de famílias de classe média e classe média superior, altamente escolarizadas.

As famílias desses três bairros encontram-se em forte situação de dependência, em função fundamentalmente do trabalho que desempenham, já que a maior parte dos adultos do bairro Céu Azul trabalham ou prestam serviço para as famílias de classe média dos outros bairros. Estas, por sua vez, dependem estreitamente desses trabalhos. É a presença das babás e das empregadas domésticas, por exemplo, que viabiliza a participação das mulheres de classe média no mercado de trabalho.

Focalizando famílias de grupos populares e médios, que contam com adolescentes entre 13 e 14 anos vivendo com os pais e que se dispuseram a conversar sobre sua história de vida e seus planos para o futuro, foram realizadas observações e entrevistas com 14 jovens e 17 adultos responsáveis por eles. Por escolha das próprias famílias, os adultos entrevistados foram, na quase totalidade dos casos, as mães. Em um caso, foi entrevistado também o pai. Em dois outros casos, a mãe foi substituída. No primeiro, a mãe teve que acompanhar inesperadamente outra filha, grávida, ao médico e foi substituída pelo pai. No outro, foi entrevistada a prima com quem vive uma garota de 14 anos que perdeu a mãe, vítima de AIDS. No caso de duas famílias dos grupos populares, houve entrevista também com as avós (uma materna e outra paterna), que estão muito engajadas na rede de apoio que viabiliza os cuidados com os jovens focalizados. A partir dessas entrevistas foi sistematizado um conjunto de dados tanto sobre a maneira como se apresentam as disposiçóes quanto ao futuro nos adolescentes dos diferentes grupos, quanto sobre as experiências educativas a que estiveram expostos. A preocupação em construir as entrevistas como histórias de vida tornou possível também reunir uma série de informações sobre os percursos sociais das famílias, que permitiu ultrapassar a simples constatação da existência de uma associação entre disposições e experiências educativas para problematizar tal associação e indagar sobre as condições que a tornaram possível. 
Fronteiras imaginadas: experiências educativas e construção das disposições...

Sem grandes surpresas, verificamos que, em consonância com os resultados encontrados por pesquisas deste tipo, realizadas em outros países (Wacquant, 1987) e mesmo no Brasil (Gunther \& Gunther, 1998), é possível descrever um forte e recorrente ajustamento entre as disposições quanto ao futuro expressas pelos jovens e as chances objetivas que eles de fato têm de implementá-las (Bourdieu, 1998). Essa questão será discutida na primeira parte do texto. A seqüência do texto dedica-se a explicar esse ajustamento. Em primeiro lugar, foi possível relacionar as disposições quanto ao futuro apresentadas pelos jovens com o percurso social de suas famílias, sobretudo no que se refere à direção e sentido desse percurso. Assim, adolescentes de famílias em situação de ascensão social são mais ambiciosos quanto ao futuro do que aqueles cujas famílias encontram-se em situação de desclassificação social (Almeida, 2001), independente do ponto da escala em que se encontram. Em segundo lugar, a pesquisa verificou uma associação significativa entre a estrutura do patrimônio, material e simbólico, de que dispõem as famílias e a maneira como essas organizam seus investimentos relativos ao futuro dos filhos, mas também a maneira como os próprios jovens aceitam e compartilham esses investimentos (Perosa, 2006). Essas são as questões discutidas no segundo item. No entanto, a pesquisa mostrou também que o veredito escolar sobre o desempenho dos jovens exerce uma influência significativa na maneira como esses patrimônios são investidos. Essa é a questão de que trata o terceiro e último item do texto.

É importante notar, desde já, que as fronteiras simbólicas observadas entre os jovens focalizados nesse estudo não seguem algumas das fronteiras sociais que os distinguem na vida cotidiana, não se encaixando, assim, de forma perfeita nas oposições "bairro de baixa renda $\mathrm{x}$ bairro de renda média" e "escola pública x escola privada", por exemplo. A importância deste ponto será discutida no final do texto.

\section{Expansão escolar e realismo da posição}

Uma das principais características das disposições quanto ao futuro, expressas pelos jovens entrevistados para essa pesquisa, é seu ajustamento às chances objetivas de realizá-las. Isso provoca clivagens evidentes entre eles. No entanto, isso não é tão evidente.

No que diz respeito especificamente às disposições com relação aos estudos expressas pelos jovens entrevistados, por exemplo, o grupo 
aparece, à primeira vista, como bastante homogêneo, sendo possível identificar um forte elemento comum a todos eles: sua intenção de chegar ao ensino superior. Isso deve ser interpretado como um dos efeitos da expansão da escolarização ocorrida na sociedade brasileira na última década, que traz em seu bojo uma modificação significativa na maneira como as fronteiras presentes no interior do sistema de ensino são percebidas. Na medida em que certos grupos sociais tradicionalmente alijados do ensino superior vêem aumentar suas chances objetivas de chegar até esse nível de ensino, mudam as percepções que o definem, transformando-o em algo "possível", "desejável” e mesmo "obrigatório", embora nunca "natural" ou "automático", como é o caso para seus congêneres dos grupos médios e superiores.

As clivagens permanecem, portanto, e podem ser percebidas na maneira como se formula o desejo. Para os jovens dos grupos médios, como já notado na bibliografia especializada (Nogueira, 2000), o ensino superior aparece como algo natural e quase automático, sobre o qual se fala com bastante familiaridade e conhecimento de causa:

"Eu quero fazer Educação Física. Tem dois tipos de Educação Física, uma trabalha com o corpo, outra trabalha com o aluno. Eu queria fazer [esse curso] para trabalhar em academia, tipo personal [trainer], para depois montar minha própria academia" (Flávio, 13 anos, aluno de escola privada; pai engenheiro químico em grande empresa do setor privado; mãe concluiu ensino médio, dona de casa).

Para os jovens dos grupos populares, no entanto, a realidade se apresenta de outro modo e percebem o ensino superior como algo que ainda está para ser garantido e que talvez esteja acima de suas forças. Daí a recorrência de expressóes como "talvez" e "se der". Esses jovens vão nomear menos frequentemente um curso preciso, falando mais genericamente em "fazer faculdade". Vê-se que o ensino superior é percebido como uma necessidade na luta contra o desemprego ou contra os trabalhos manuais extenuantes que esses adolescentes vêem os adultos à sua volta desempenhando:

"Mais para a frente eu estava pensando em fazer faculdade.... se der (...). $\mathrm{Eu}$ acho que é importante porque, para prestar concurso, tem sempre que ter estudo" (Delmo, 14 anos, aluno de escola pública; pai $3^{\text {a }}$ série do ensino fundamental, trabalhava na pequena lavanderia do pai e está aposentado por invalidez; mãe concluiu ensino médio supletivo recentemente, empregada doméstica diarista). 
Fronteiras imaginadas: experiências educativas e construção das disposições...

A clivagem seguinte, ainda no que diz respeito aos estudos, é dada pela maneira como se expressa o percurso até o ensino superior. Encontramos, assim, no grupo focalizado um contínuo entre aqueles que construíram planos detalhados para chegar ao ensino superior:

"Eu tenho planos de me formar em engenharia mecatrônica. [Vou fazer] como a minha irmã... Ela fez colégio técnico, fez estágio. Então agora ela estuda e fica trabalhando à tarde. Então eu tenho vontade de enquanto estiver na faculdade juntar dinheiro. E depois da faculdade tentar fazer negócios" (Paulo, 13 anos, aluno de escola privada, pai engenheiro elétrico que trabalha como consultor em grande empresa e mãe psicóloga que atende em consultório privado).

"No ano que vem, vou estudar no B [colégio público] (...). Depois que terminar o segundo grau vou prestar faculdade de propaganda, me formar e trabalhar nesse ramo" (Dante, 14 anos, aluno de escola pública; pai concluiu o ensino fundamental e fez curso técnico em eletrônica no SENAI, pequeno empresário; mãe estudou até à $8^{a}$ série, dona de casa).

E aqueles que expressam disposições para investir no ensino superior de forma mais abstrata:

"Eu também acho que, se eu continuar estudando, vou ter um futuro... um futuro melhor. Tudo bem que hoje em dia está difícil, mas... é o que eu pretendo... mostrar o melhor, fazer um curso, uma faculdade completa... é o que eu pretendo" (Anelise, 13 anos, aluna de escola pública, pai estudou até à $3^{a}$ série do ensino fundamental, empregado em serviços gerais no setor privado; mãe estudou até à $5^{\text {a }}$ série, funcionária de escola pública).

Além dessa dimensão relativa à relação com os estudos, os jovens se distinguem também por suas disposições quanto ao trabalho. Num primeiro eixo, há diferenças no que diz respeito ao momento em que se deve ou se pretende "procurar um trabalho". No grupo em questão, isso variou de um extremo, no qual a entrada no mercado de trabalho é pensada como algo a ser encarado concomitantemente ao final do ensino superior, até o oposto, em que isso é percebido como futuro imediato, isto é, quando completarem a idade em que podem legalmente estabelecer um contrato de trabalho, e desejável.

Num segundo eixo, as disposições com relação ao trabalho variaram em função da ocupação ou do modo de exercício desta considerados interessantes ou desejáveis. Num extremo estão os jovens cuja preocupação é, 
fundamentalmente, evitar o tipo de trabalho manual desempenhado pelos adultos que os cercam. Esses adolescentes querem um trabalho "mais leve", "menos controlado", "que não seja de faxineira", "que não seja de jardineiro", "que não [tenha] que trabalhar em pé" etc. No outro extremo estão os jovens que buscam posições de comando e de autonomia: "montar minha construtora", "montar uma academia de ginástica", "abrir empresa de moda" e mesmo "operar na bolsa de valores".

Como mostra a tabela 1 , essas diferenças não se distribuem de forma aleatória entre o grupo em foco, mas seguem de perto as linhas demarcatórias dadas pelas posiçôes sociais ocupadas pelas famílias, comprovando o realismo preciso no qual vivem mergulhados os adolescentes.

Que mecanismos permitem esse ajustamento fino entre disposições quanto ao futuro e posição social dos pais vivenciado no mais das vezes, pelos adolescentes, como vocação ou mesmo idiossincrasia?

Há uma significativa tendência na literatura a explicar isso pelo viés da "cultura". A desconfiança com relação à escola e a busca do trabalho precoce típicos de famílias dos grupos populares, assim como o seu oposto encontrado nas famílias dos grupos médios, seriam decorrentes de uma visão de mundo particular. Embora o raciocínio seja de difícil contestação, ele não explica praticamente nada, a não ser que se tome como problema explicar o que causa a cultura. Assim, aceitando-se que as percepções e os comportamentos a que dão origem sejam regidos por sistemas simbólicos, que podemos denominar como "cultura", como explicar que determinados sistemas simbólicos tenham sido desenvolvidos ou apropriados por determinados grupos e não outros?

Para responder a essas perguntas é necessário se dar ao trabalho de buscar a gênese desses sistemas simbólicos, arcabouços estruturados de modos de compreensão e de percepção do mundo, por meio do exame das condições sociais no interior das quais eles foram gestados (Bourdieu, 1958; Bourdieu \& Sayad, 1964). Recorremos, assim, às informaçôes obtidas por meio das entrevistas que nos permitissem organizar uma explicação.

Essas entrevistas nos mostram, em primeiro lugar, que as disposições quanto ao futuro são formuladas no quadro, por um lado, de um processo de individualização que se coloca com premência para os adolescentes desta idade de forma generalizada, embora mais forte entre os adolescentes dos grupos populares (Elias, 1994). Esse processo é vivido 


\section{Tabela 1}

(Relação entre as disposições dos jovens quanto ao futuro escolar e à entrada no mercado de trabalho e a ocupação e escolarização dos pais)

\begin{tabular}{|c|c|c|c|}
\hline Nome & $\begin{array}{l}\text { Disposição quanto ao } \\
\text { futuro escolar }\end{array}$ & $\begin{array}{l}\text { Disposição quanto à entrada } \\
\text { no mercado de trabalho }\end{array}$ & $\begin{array}{c}\text { Ocupação e escolarização } \\
\text { dos pais }\end{array}$ \\
\hline $\begin{array}{c}\text { Fábio } \\
\text { (escola pública) }\end{array}$ & $\begin{array}{l}\text { EM EP NP diurno, exército. } \\
\text { "Talvez" faculdade. }\end{array}$ & $\begin{array}{l}\text { Depois do EF. Em loja ou } \\
\text { mercado "que não canse muito". }\end{array}$ & $\begin{array}{l}\text { Pai } 7^{\text {a }} \text { série, pintor de } \\
\text { paredes; mãe } 5 \text { a série, } \\
\text { empregada doméstica. }\end{array}$ \\
\hline $\begin{array}{c}\text { Júlia } \\
\text { (escola pública) }\end{array}$ & $\begin{array}{l}\text { EM EP NP noturno, } \\
\text { "faculdade, se der". }\end{array}$ & $\begin{array}{c}\text { Depois do EF. } \\
\text { "Qualquer coisa eu pego". }\end{array}$ & $\begin{array}{l}\text { Orfā. Tia } 7^{\text {a }} \text { série supletivo, } \\
\text { empregada doméstica. }\end{array}$ \\
\hline $\begin{array}{c}\text { Diana } \\
\text { (escola pública) }\end{array}$ & $\begin{array}{l}\text { EM EP NP noturno, } \\
\text { "ter o meu diploma na mão". }\end{array}$ & $\begin{array}{c}\text { Nāo sabe. Já "ajuda" } \\
\text { a avó babá. }\end{array}$ & $\begin{array}{c}\text { Pai desempregado; mãe } 7^{\mathrm{a}} \\
\text { série supletivo, empregada } \\
\text { doméstica. }\end{array}$ \\
\hline $\begin{array}{c}\text { Anelise } \\
\text { (escola pública) }\end{array}$ & $\begin{array}{l}\text { EM EP NP noturno, } \\
\text { "faculdade" }\end{array}$ & $\begin{array}{l}\text { Depois do EM. } \\
\text { "Não ser faxineira". }\end{array}$ & $\begin{array}{l}\text { Pai } 3^{\text {a }} \text { série, serviços gerais, } \\
\text { setor privado; mãe } 5^{\text {a }} \text { série, } \\
\text { func. pública. }\end{array}$ \\
\hline $\begin{array}{c}\text { Leandro } \\
\text { (escola privada) }\end{array}$ & EM, "faculdade". & $\begin{array}{l}\text { Depois da faculdade. } \\
\text { Um trabalho em que nāo } \\
\text { "fosse controlado toda hora". }\end{array}$ & $\begin{array}{l}\text { Pai ensino fundamental, } \\
\text { motorista particular, } \\
\text { desempregado; māe EM } \\
\text { téc., funcionária pública. }\end{array}$ \\
\hline $\begin{array}{c}\text { Dirceu } \\
\text { (escola pública) }\end{array}$ & $\begin{array}{l}\text { EM técnico, colégio privado. } \\
\text { Faculdade Propaganda. }\end{array}$ & $\begin{array}{c}\text { Depois do EF. Atendente em } \\
\text { supermercado (oposiçāo do pai). }\end{array}$ & $\begin{array}{l}\text { Pai EF + SENAI, pequeno } \\
\text { empresário; mãe } 8^{\mathrm{a}} \text { série, } \\
\text { dona de casa. }\end{array}$ \\
\hline $\begin{array}{c}\text { Delmo } \\
\text { (escola pública) }\end{array}$ & $\begin{array}{l}\text { EM técnico eletrônica, colégio } \\
\text { privado. Faculdade "se der". }\end{array}$ & $\begin{array}{l}\text { Depois da faculdade. } \\
\text { Trabalhar sentado. }\end{array}$ & $\begin{array}{l}\text { Pai } 4^{\text {a }} \text { série, aposentado; } \\
\text { mãe } 2^{\circ} \text { grau supletivo. }\end{array}$ \\
\hline $\begin{array}{c}\text { Carlos } \\
\text { (escola privada) }\end{array}$ & $\begin{array}{l}\text { EM NP ou técnico, } \\
\text { "faculdade". }\end{array}$ & $\begin{array}{l}\text { Depois de formado, na firma } \\
\text { do pai, mas queria Artes. }\end{array}$ & $\begin{array}{l}\text { Pai EM técnico, } \\
\text { empresário médio porte; } \\
\text { mãe EM magistério. }\end{array}$ \\
\hline $\begin{array}{c}\text { Amália } \\
\text { (escola privada) }\end{array}$ & $\begin{array}{l}\text { EM talvez técnico. } \\
\text { Faculdade de Turismo } \\
\text { "por ser mulher". }\end{array}$ & $\begin{array}{l}\text { Depois da faculdade. } \\
\text { Conciliar com o cuidado } \\
\text { com os filhos. }\end{array}$ & $\begin{array}{l}\text { Pai Medicina setor público; } \\
\text { mãe Adm. de Emp., } \\
\text { dona de casa. }\end{array}$ \\
\hline $\begin{array}{c}\text { Gustavo } \\
\text { (escola privada) }\end{array}$ & $\begin{array}{l}\text { EM técnico, colégio público. } \\
\text { Universidade não decidida. }\end{array}$ & $\begin{array}{l}\text { Depois da faculdade. } \\
\text { Conciliar universidade } \\
\text { com aptidão artística. }\end{array}$ & $\begin{array}{l}\text { Pai Eng. Eletrotécnico, prof. } \\
\text { universidade pública; mãe } \\
\text { Ed. Física, func. pub. }\end{array}$ \\
\hline $\begin{array}{c}\text { Flávio } \\
\text { (escola privada) }\end{array}$ & $\begin{array}{l}\text { Ensino médio técnico } \\
\text { colégio público. } \\
\text { Educação Física. }\end{array}$ & $\begin{array}{l}\text { Depois de formado. } \\
\text { Montar academia de ginástica. }\end{array}$ & $\begin{array}{l}\text { Pai Eng. Químico setor } \\
\text { privado; mãe EM, venda } \\
\text { catálogo, dona de casa. }\end{array}$ \\
\hline $\begin{array}{c}\text { Silvana } \\
\text { (escola privada) }\end{array}$ & $\begin{array}{l}\text { EM técnico, colégio público. } \\
\text { Faculdade Publicidade. }\end{array}$ & $\begin{array}{l}\text { Depois de formada. Abrir } \\
\text { empresa de moda, "construir } \\
\text { patrimônios". }\end{array}$ & $\begin{array}{l}\text { Mãe Eng. de Alimentos, } \\
\text { prof. universidade pública } \\
\text { (viúva, s/d pai). }\end{array}$ \\
\hline $\begin{array}{c}\text { Vinícius } \\
\text { (escola privada) }\end{array}$ & EM NP, Engenharia Civil. & $\begin{array}{l}\text { Depois de formado. Montar } \\
\text { uma construtora. }\end{array}$ & $\begin{array}{l}\text { Pai Químico, prof. } \\
\text { universidade privada; mãe } \\
\text { Nutrição, func. pública. }\end{array}$ \\
\hline $\begin{array}{c}\text { Paulo } \\
\text { (escola privada) }\end{array}$ & $\begin{array}{l}\text { EM técnico informática } \\
\text { colégio público. Engenharia } \\
\text { Mecatrônica universidade } \\
\text { pública. }\end{array}$ & $\begin{array}{c}\text { Estágios durante a faculdade. } \\
\text { Depois de formado operar na } \\
\text { bolsa de valores. }\end{array}$ & $\begin{array}{l}\text { Pai Eng. Elétrico setor } \\
\text { privado; māe Psicologia } \\
\text { consultório particular. }\end{array}$ \\
\hline
\end{tabular}

Legenda: EM (ensino médio); EP (escola pública); NP (não-profissionalizante). Fonte: Entrevistas de pesquisa. 
como um desejo de independência relativo principalmente ao consumo, o que pode ser explicado pelas condiçôes econômicas das famílias, mas também, e de forma importante, relativo à liberdade para sair com os amigos, o que é um indicador do controle que essas famílias exercem sobre os jovens e que também pede por explicação. Por outro lado, as disposições quanto ao futuro são formuladas também na tensão com o processo de incorporação na linhagem familiar, que faz com que os desejos e as recusas sejam formulados na relação com os adultos mais significativos com quem convivem os adolescentes. O grupo familiar é, nesse sentido, uma unidade analítica fundamental e a busca pela gênese das disposições sobre o futuro, compreendida como uma busca pelas condições objetivas que permitiram sua construção, pode ser empreendida por meio do exame detido dos itinerários sociais dessas famílias.

Assim, nosso objetivo foi, fundamentalmente, procurar nessas trajetórias os elementos que nos permitissem qualificar as condiçōes objetivas de existência de cada grupo e suas transformações ao longo do tempo, buscando explicitar a experiência da abundância ou da escassez, da estabilidade ou da instabilidade. Verificamos isso tanto com relação aos recursos materiais, quanto com relação à proximidade com a cultura legítima, utilizando como indicador, nesse caso, a escolarização dos membros das famílias (Almeida, 2007). Em seguida, procuramos relacionar tais condiçôes objetivas com os investimentos educativos de fato realizados.

\section{Trajetórias, patrimônios e destino}

As entrevistas realizadas mostram uma associação estreita entre o sentido dos percursos sociais das famílias e as disposiçôes dos adolescentes com relação ao futuro. Assim, por um lado, os adolescentes mais ambiciosos são aqueles cujas famílias encontram-se em situação de ascensão social, entendida aqui como melhora das suas condições objetivas ao longo de um período de tempo. $\mathrm{Na}$ maioria dos casos, essa melhora das condições se desdobra por pelo menos duas geraçôes. Por outro lado, embora percursos absolutamente descendentes não possam ser detectados no grupo analisado, por razóes que serão discutidas mais à frente, é possível ver que os adolescentes menos ambiciosos são aqueles cujas famílias estão amarradas na luta para evitar a miséria. 
Fronteiras imaginadas: experiências educativas e construção das disposições...

Para se compreender melhor essa questão, é importante ter em mente que o percurso social das famílias em foco é fundamentalmente marcado pela mobilidade, inclusive geográfica. Essa coincidência não é acidental, mas resultado da nossa decisão de concentrar a pesquisa nesses bairros específicos, marcados por uma rápida complexificação da estrutura produtiva da região onde se localiza a cidade, acompanhada por um forte aumento populacional, um dos reflexos da reestruturação que acompanhou a crise econômica dos anos de 1980. A cidade hoje está no centro de um dos principais eixos de expansão industrial do interior do estado de São Paulo (Nobre, s/d), dispondo ainda de uma sólida base de produção agrícola, tendo se tornado, ao longo dos anos de 1980, um dos pólos de atração dos movimentos migratórios até então concentrados fundamentalmente na Região Metropolitana de São Paulo (Baeninger \& Rodrigues, s/d).

As famílias focalizadas nesse estudo foram protagonistas desses processos que culminaram, sem exceção, numa melhoria nas suas condições gerais de vida advinda, principalmente, da chegada a um centro urbano com maior oferta de infra-estrutura (residências servidas por rede de água encanada, eletricidade e esgoto), equipamentos coletivos (creches, escolas, hospitais etc.), empregos melhor remunerados ou que, pelo menos, permitissem certa folga na renda para o consumo. Esse processo foi associado a um avanço generalizado na escolarização que acompanhou a tendência geral da população brasileira nas últimas décadas.

Para compreender o sentido dessas transformações, é importante distinguir desde já "melhoria nas condições de vida" de "ascensão social”, já que nem sempre a melhoria nas condiçôes de vida se deve a casos de ascensão social no sentido mais preciso do termo. Talvez seja importante lembrar, nesse ponto, que os estudos sobre mobilidade social tratam como ascensão social apenas os casos em que a ocupação dos filhos supera a ocupação dos pais, numa classificação hierárquica ocupacional que leve em consideração as modificações ocorridas na própria classificação ocupacional num determinado período do tempo (Scalon, 1999; Ribeiro, 2003). ${ }^{3}$

Assim, o fato de que uma das avós entrevistadas tenha afirmado que "faltava tudo em casa, comida em primeiro lugar" e que seus netos "fazem cara feia e deixam comida no prato quando não gostam do que tem para o almoço" é um indício de melhoria nas condições de vida, assim 
como são também indícios dessa melhoria o fato de morarem em casa própria, num bairro com esgoto, água encanada, transporte coletivo na porta e escola a dois quilômetros de distância, tendo o avô crescido numa região rural do interior do Pará, sem luz elétrica, sem escola por perto, tendo que andar duas horas para chegar à escola onde cursou até à $2^{\text {a }}$ série. No entanto, o fato de que seu marido tenha se aposentado como cortador de carne em açougue e que seu filho seja hoje pedreiro, tendo abandonado a escola na $7^{\text {a }}$ série, indica que não houve ascensão de uma geração para outra.

No entanto, é importante notar também que praticamente todas as famílias focalizadas aqui viveram processos mais ou menos dramáticos de instabilidade social. Para as famílias que já podiam se classificar como classe média na geração dos avôs dos adolescentes, por exemplo, principalmente aquelas mais escolarizadas, alguns processos como as transformações no setor bancário que implicaram num encolhimento significativo da mão de obra empregada (Segnini, 1999), assim como as privatizações das grandes empresas de telecomunicações e eletricidade (Sabóia, 2005) implicaram perda de emprego por parte de homens e mulheres, tendo desempenhado um papel fundamental na conformação de suas trajetórias, impondo, no entanto, mais reconversões do que desclassificações (Saint Martin, 1976), o que de certa maneira não deixa de demonstrar a garantia representada pelo diploma de ensino superior no que diz respeito à inserção no mercado de trabalho. As famílias dos grupos populares focalizadas aqui, por sua vez, dependem, em sua maioria, de empregos na construção civil, um setor que não sofreu oscilações tão extremas ao longo dos anos de 1990 como o bancário, por exemplo, apresentando mesmo uma certa expansão (Cacciamali, 1995; Sabóia, 2005). Assim, embora períodos de ausência de trabalho tivessem sido identificados, sua relativa brevidade permite que os entrevistados mostrem confiança de que o trabalho "sempre aparece", como vários afirmaram, embora os intervalos constantes entre um serviço e outro sejam vividos com bastante ansiedade e desorganizem de fato o orçamento apertado das famílias.

Em vista disso, não foi surpresa constatar que a instabilidade das posições foi um elemento comum à maioria dessas famílias, sendo que as clivagens operatórias concentram-se, portanto, mais na presença ou ausência de melhoria nas condições de vida, percebidas ou não como ascensão ou desclassificação social, e na estrutura dos patrimônios. 
Fronteiras imaginadas: experiências educativas e construção das disposições...

É isso o que separa, por exemplo, a situação da família de um adolescente como Fábio - que pretende cursar o ensino médio e depois "ir para o exército", porque o pai lhe disse que é uma saída interessante para conseguir um emprego "que não canse muito" e depois, "se der", cursar alguma faculdade - da situação da família de Paulo, que pretende fazer o curso técnico num colégio público (cujos resultados no ENEM superaram os resultados de todos os colégios privados da cidade) e, em seguida, Engenharia Mecatrônica numa universidade pública prestigiosa para, depois, "operar na bolsa de valores".

\section{"Não como o pai"}

A instabilidade da posição na família de Fábio diz respeito ao risco da miséria propriamente dita, da falta do que comer, da impossibilidade de pagar as contas de água e luz ou de poder comprar algum extra para o filho ou para a casa. Esse risco é vivido de forma constante porque o pai do Fábio é pintor de paredes e trabalha como autônomo. Ao final de cada serviço, renova-se na família a angústia frente a possibilidade de não aparecer um outro ou de demorar demais. Nos períodos sem trabalho, as despesas são garantidas pelo salário mínimo que a mãe ganha como doméstica, trabalhando meio período numa casa de família nas proximidades. A família participa também do circuito de ajuda e de trocas de favores que envolve os avós paternos e a família do tio paterno de Fábio, todas dividindo o mesmo terreno que pertence aos avós de Fábio. Nos períodos sem trabalho, por exemplo, a avó, empregada doméstica, assume a parte deles nas contas que são pagas em comum (água, luz, IPTU), sendo essas "dívidas” pagas com exatidão quando a situação fica mais folgada.

A instabilidade da renda paterna é vivida como um grande problema pela mãe de Fábio, que se viu na necessidade de "vender" suas férias nos últimos três anos para arcar com os períodos em que o marido está sem serviço. Ela se queixa de muito cansaço e diz que gostaria muito de parar de trabalhar, caso "ele [marido] tivesse um emprego fixo". ${ }^{4}$ Tudo se passa assim como se as energias do casal estivessem todas canalizadas para essa questão básica de garantir a sobrevivência semana após semana.

A instabilidade é percebida, pela mãe de Fábio pelo menos, como um resultado da recusa do seu marido ao emprego fixo "com carteira 
assinada". No entanto, trabalhar "por conta [própria]" é uma questão de honra para o pai de Fábio, que entende o emprego fixo como sinônimo de "abaixar a cabeça". Ele explica que "esse negócio de trabalhar em firma é ruim porque você não sabe quem é que manda. Todo mundo quer mandar". Trabalhar como autônomo ou "por conta", como ele diz, "é melhor, porque você não tem que ficar pagando pau para os outros”. Essa percepção é compartilhada também por seu irmão, um ano mais novo que ele.

O mesmo espírito de insubmissão, que pode ser percebido também como uma maneira de vivenciar a masculinidade, parece ter guiado a relação do pai de Fábio e seu irmão com a escola que abandonaram aos 13 e 14 anos, respectivamente, na $7^{\text {a }}$ série. Embora o pai de Fábio tenha repetido apenas uma série e por motivo de doença, não tendo o tio chegado a repetir nenhuma, o abandono da escola foi precedido por incontáveis episódios de brigas e enfrentamentos tanto com os colegas, quanto com os professores. Sua mãe nos contou que era rara a semana em que ela não era chamada na escola para ouvir reclamações sobre o (mau) comportamento dos filhos. Embora afirmando hoje que a escola por onde passou (a mesma onde estuda hoje o seu filho) é uma "boa escola", o pai de Fábio resolveu investir no trabalho precocemente, passando a trabalhar aos 13 anos como ajudante do tio materno que era pedreiro.

Tendo sido criados para "ter uma profissão", como nos conta sua mãe, que tentou matricular os filhos em diversos cursos profissionalizantes de boa reputação oferecidos gratuitamente por instituições religiosas na cidade, confrontando-se sempre com a recusa de ambos em ingressar nesse caminho, os dois irmãos eram, até essa idade, bastante controlados no que diz respeito aos resultados escolares, ao dinheiro e às companhias, não tendo autorização para fazer quase nada sozinhos.

Isso, junto com o desacerto com a escola, parece estar na origem da decisão de ambos de começar a trabalhar "para ganhar dinheiro, para sair", como contou o pai de Fábio. Optando pelo trabalho com o tio, pedreiro que já conseguira uma clientela e um certo nome na cidade, ele garantiu uma autonomia financeira razoável que lhe permitia sair "de casa na sexta-feira e voltar na segunda", situação que ele hoje lembra com uma ponta de nostalgia e orgulho. No entanto, ao fazer o serviço militar obrigatório, percebeu ali uma segunda chance na escola, 
Fronteiras imaginadas: experiências educativas e construção das disposições...

decidindo-se por se profissionalizar no exército. Enquanto ainda estava no quartel, a gravidez inesperada da namorada de 20 anos que conhecera numa discoteca, num bairro próximo à sua casa, interrompeu esses planos e o pai de Fábio voltou ao trabalho como pintor de paredes, sonhando hoje com a profissionalização do filho num curso de mecânico dado pela Aeronáutica, mesmo caminho seguido por alguns dos seus amigos da época da escola.

Nesse contexto, Fábio é submetido a constrangimentos díspares e antagônicos. Por um lado, está exposto ao discurso do próprio pai, da mãe e da avó que o incitam a aplicar-se aos estudos, tendo em vista a profissionalização, construindo essa visão de futuro como uma oposição à situação vivenciada pelo pai, como nos mostram os extratos de entrevista abaixo:

"[Queria] que ele tivesse uma profissão, que ele não ficasse igual ao pai dele, que tem mês que tem serviço, tem mês que não. É triste isso aí, ainda mais para homem. Espero que ele estude bastante". (Mãe do Fábio, 34 anos, entrevista, Campinas, out. 2006).

"Se ele tiver o colegial quando ele entrar no exército (...) ele pega uma patente boa lá dentro. (...) Porque se ficar nessa que nem eu tô aí, tá na roça. Porque também esse negócio de mexer com tinta acaba com a gente, a saúde da gente". (Pai do Fábio, 33 anos, entrevista, Campinas, out. 2006).

"A gente queria que ele terminasse o colegial. Para ter uma profissão. Ficar um pouco melhor do que o pai”. (Avó paterna do Fábio, 55 anos, entrevista, Campinas, abr. 2006).

"E onde seria um bom lugar para trabalhar? Deixa eu pensar... num mercado, em lojas. Menos... é melhor do que trabalhar como o pai. Meu pai é pintor [de paredes], cansa muito. Pedreiro [ocupação do tio] também cansa. É melhor ter essa profissão, trabalhar num mercado, loja". (Fábio, entrevista, maio 2007).

Nesse sentido, a família segue de perto sua vida escolar. É o pai, por exemplo, que comparece às reuniōes com os professores. Além disso, suas saídas e amizades são estritamente controladas. Sua avó conta que o pai ameaçou deixar Fábio "roxo" se o visse fazendo amizade com "gente que não presta".

Por outro lado, Fábio está exposto a todos os constrangimentos da instabilidade econômica que o fazem perceber o trabalho imediato como uma necessidade. Assim, embora esteja sendo poupado do trabalho 
regular em nome da dedicação aos estudos, mas também porque a legislação não autoriza o trabalho antes dos 15 anos, o pai já o leva para trabalhar como ajudante na sua equipe sempre que há serviço no final de semana, recompensando-o com o salário devido, de $\mathrm{R} \$ 20,00$ por dia, que ele, entusiasmado, gasta com "refrigerante, salgadinho, bala", itens de consumo raros na sua casa.

Essa situação faz com que Fábio não hesite em afirmar: "vou fazer o segundo grau inteirinho e depois vou arrumar um trabalho". No caso desse garoto, a possibilidade da faculdade aparece apenas como resultado da pergunta direta da entrevistadora: "e a faculdade?". A resposta: "é uma boa. Acho que vou fazer. Talvez, talvez eu faça faculdade”.

\section{A exemplo do pai}

A posição mais privilegiada da família que tomaremos como exemplo de uma posição oposta a essa que acabamos de examinar não significa ausência de riscos. Ao contrário, a história familiar é contada como uma seqüência de superações de dificuldades.

Trata-se aqui de dificuldades em assegurar a continuidade de uma situação que parecia garantida no momento em que o pai de Paulo termina o curso de Engenharia Elétrica na PUC-RJ, no final dos anos de 1970, a mais prestigiosa formação da área na época, que lhe garantiu aprovação imediata em "três concursos", como nos contou sua esposa psicóloga que, à época, iniciava-se no atendimento, em consultório, a crianças com dificuldades de aprendizagem, depois de muitos anos trabalhando como professora primária.

É importante notar que as altas credenciais escolares conseguidas por um e outra são percebidas pela família como o resultado de um forte investimento pessoal e coletivo, isto é, de todo o grupo familiar que "investia tudo na escolarização dos filhos", como nos contou a mãe de Paulo. Isso deve ser compreendido como função da ainda vagarosa expansão do ensino superior, que caracterizou os anos de 1960 e 1980, embora ambos viessem de um segmento particularmente beneficiado pela pequena expansão que, não obstante, teve lugar: o pai de Paulo é filho de funcionários públicos de nível superior (estatística e contabilidade), enquanto a mãe é filha de funcionários públicos de nível médio (escriturários). 
Fronteiras imaginadas: experiências educativas e construção das disposições...

Optando por trabalhar numa empresa estatal no setor de telecomunicações, o pai de Paulo ocupou cargos de gerência logo de início: "engenheiro, engenheiro ele diz mesmo que nunca foi", afirma sua esposa. A família alcançou uma posição confortável logo no início do casamento. $\mathrm{O}$ casal conseguiu contribuir com a compra do apartamento dos pais da esposa, "ainda muito recente mesmo de casada", e, arcar com os custos de uma estrutura doméstica, duas empregadas e um motorista, que permitia à esposa cuidar dos quatro filhos que nasceram ao longo dos primeiros doze anos de casamento e trabalhar no consultório de psicologia, direcionando seu atendimento, a partir de certo momento, para terapia de adultos. Essa situação se alterou de forma substantiva com a privatização da companhia estatal em que trabalhava o pai de Paulo, forçando uma baixa de salário da ordem de $40 \%$, conforme nos contou sua esposa. Isso os levou a se transferir para a cidade em que residem hoje, onde ele encontrou uma posição como consultor que, junto com os rendimentos que obtém em investimentos esporádicos na bolsa de valores, tem garantido uma posição de classe média para a família. A esposa, por sua vez, refez paulatinamente sua clientela de consultório. Esse período de instabilidade foi vivido como uma desclassificação, como nos conta a mãe de Paulo: "você pode imaginar que eu tinha duas empregadas e passei um ano e meio sem nenhuma empregada", embora ela afirme ter sempre mantido a confiança: "eu digo que eu costumo ser Poliana, eu sempre acredito que vai dar certo, eu acredito mesmo que vai dar certo". Eventualmente, as coisas se ajeitaram, "agora o meu consultório está cheio", como comprova seu indicador preferido: "voltei a ter empregada, naturalmente".

Devendo a mobilidade ascendente da família às credenciais escolares, não é surpresa que os investimentos na educação dos filhos priorizem essa dimensão, embora o período de contenção por que passaram tenha definido a forma particular que esses assumem hoje. A família utiliza os conhecimentos de que dispõe para orientar as trajetórias dos filhos por entre escolas privadas e públicas escolhidas a dedo e para utilizar de forma racional todos os recursos que controla. É nessa lógica, por exemplo, que estadias no estrangeiro foram garantidas aos irmãos mais velhos de Paulo, por meio um programa transnacional que promove o intercâmbio de jovens com fins educacionais tanto no próprio país quanto no estrangeiro. Isso só foi possível pelo investimento pessoal do pai de Paulo como voluntário na associação. O próprio Paulo, bastante animado com o programa de que participa desde os onze anos, 
tem uma boa percepção do custo arcado pelo pai: “ah, é um saco. Você [o pai voluntário] tem que fazer um monte de coisa, tem que viajar de uma cidade para outra”.

Além disto, há também um cuidado particular com as questôes relacionadas a dinheiro e trabalho. Aos 13 anos, Paulo recebe uma mesada mensal e é auxiliado na organização dos seus gastos. Ele explica:

\begin{abstract}
"Tudo o que eu faço, faço com o meu dinheiro. Tipo, eu recebo, eu faço um planejamento anual e eu sei quanto vou receber todos os meses e eu tenho uma planilha e tenho que fazer um planejamento de quanto eu posso gastar em cada mês". Se num mês você gastar muito... "Mas aí eu tenho que saber quanto eu posso gastar." Você nunca passa dos limites? "Já passei." E aí? "Só que eu recompenso com dinheiro de presentes, normalmente no meu aniversário eu ganho dinheiro da minha avó. Aí eu anoto fora do orçamento. Se eu sair... eu tenho aquele dinheiro". Ah, então, se sair... "É. Todo fim de mês eu sento com o meu pai com a planilha junto e vejo se gastou muito aqui, se gastou ali". Você recebe todo mês uma quantia fixa? "Nos cinco primeiros meses, uma, nos outros meses, outra, porque tem coisas... é mais pesado agora no começo. Então eu tenho que calcular isso para não ficar no vermelho". (Paulo, 13 anos, entrevista de pesquisa, abr. 2007).
\end{abstract}

Com relação ao trabalho, por exemplo, o pai de Paulo já orienta o outro filho, mais velho e já cursando uma universidade pública de renome, a realizar pequenos investimentos na bolsa de valores. Como resultado, afirma Paulo, ele "consegue ganhar um dinheiro até bem considerável”.

Com todo esse investimento, não é de se estranhar que Paulo perceba seu futuro se desenvolvendo em áreas próximas à do pai. "Meu pai, ele é bem voltado para a matemática", como ele diz, explicando que na casa dele as duas irmãs "nunca foram para a área de matemática, enquanto que "eu e o Marcelo [irmão] fomos para a matemática". No caso de Paulo, ir para a matemática culminaria num curso de Engenharia Mecatrônica numa universidade pública prestigiosa.

\title{
A força do veredito escolar
}

A análise aqui apresentada não ficaria completa sem uma discussão sobre a tendência notada de as famílias guiarem os investimentos escolares dos filhos em função do veredito da escola. 
Fronteiras imaginadas: experiências educativas e construção das disposições...

Tanto no caso das famílias dos grupos populares, quanto no caso das famílias dos grupos médios, as ambições dos alunos só deixam de se correlacionar perfeitamente com a posição social de suas famílias quando a escola acena num sentido diferente daquele que é esperado.

O caso de uma adolescente desse grupo é, nesse sentido, exemplar. Amália é filha de um médico e de uma nutricionista que atuam no setor público. Destinada a um futuro escolar de prestígio, foi matriculada em uma escola tradicional considerada como bastante exigente no início de sua escolarização. No entanto, enfrentou uma série de dificuldades na alfabetização que só foram contornadas com ajuda de fonoaudióloga e psicóloga. No meio tempo, Amália viu-se colecionando notas baixas. Diante desta situação, a família decidiu procurar um colégio que pudesse acolher essas dificuldades, chegando à escola onde Amália foi encontrada pela pesquisa. Ela explica:

"Eles [os profissionais da escola anterior] não ligavam... as matérias passavam batido, mas eles iam bem mais para a frente do que aqui. Aqui eles fazem diferente, eles querem que você pegue a matéria em vez de passar tudo batido... Lá eles não se importavam com isto". (Amália, 14 anos. Entrevista de pesquisa, abr. 2007).

Não obstante o acolhimento dado pela nova escola, os sonhos de Amália são bem modestos, subordinando seus desejos para o futuro com a necessidade de que diz sentir de se preparar para "dar atenção para a minha família, para os meus filhos". Ela se diz em crise de identidade e que é "meio triste” reconhecer que "já" cresceu. Embora acene vagamente com a possibilidade de seguir um curso técnico em Turismo, logo se corrige, afirmando: "eu acho que não vou conseguir dar conta de tudo porque... eu tenho esse ritmo". Considera, então, mais provável seguir um curso secundário não-profissionalizante e uma faculdade de Turismo que lhe permitiria, nas suas palavras, praticar "outras línguas que talvez possam ajudar meus filhos a se especializarem melhor no futuro".

$\mathrm{O}$ fato de que isso possa acontecer com relação a adolescentes oriundos de famílias com recursos suficientes para tentar escapar do veredito da escola mostra o quanto o sistema escolar brasileiro encontrase autonomizado com relação às demandas das famílias. Essa não é, claro, uma conclusão isolada, mas vem ao encontro de uma série de outros estudos que têm mostrado a mesma coisa, principalmente com relação 
às "trajetórias improváveis" dos estudantes dos grupos populares (Portes, 1993; Viana, 1998; Zago, 2006; Almeida, 2007), cujo exame deixa clara a contribuição da escola, principalmente pública, para a extensão da trajetória escolar de jovens desses grupos, oferecendo um combustível para além dos recursos que podem ser mobilizados por suas famílias.

\section{Considerações finais}

A pesquisa que deu origem a esse artigo teve como objetivo examinar os mecanismos que contribuem para a produção de visões de mundo responsáveis por orientar os investimentos dos indivíduos numa direção ou noutra, definindo proibiçōes e possibilidades.

Trata-se aqui de uma questão fundamental para o melhor entendimento da persistência dos altos níveis de desigualdades presentes na sociedade brasileira, na medida em que nos convida a tomar essas desigualdades como algo que se constrói dia a dia também a partir das interaçôes concretas em que se engajam os membros desta sociedade.

Compreender a visão de mundo como algo que se constrói a partir de condiçōes concretas de existência, e não por um legado não tangível que uma geração transmite à seguinte, tem implicações bastante significativas. Assim, se é verdade que as disposições quanto ao futuro expressas pelos adolescentes focalizados nessa pesquisa são visivelmente vinculadas à história concreta do seu grupo familiar que, por sua vez, está atrelada à história do grupo social mais amplo de que este faz parte, isto é, à sua posição de classe, a pesquisa mostrou que sua construção depende de uma exposição consistente e significativa a condiçôes concretas de existência que possam confirmar ou negar os destinos de classe previamente traçados.

A pesquisa mostrou que, embora as disposiçōes quanto ao futuro expressas pelos jovens entrevistados sejam em grande parte determinadas pelo sentido da trajetória do grupo familiar (ascendente, descendente ou simplesmente estagnada) e pela estrutura dos patrimônios, material e simbólico, de que dispõem, o espaço para indeterminações não é pequeno.

Mais estudos são, portanto, necessários, para que se possa estabelecer com mais clareza as condições necessárias para que o espaço de indeterminação possa ser politicamente trabalhado, isto é, preenchido 
Fronteiras imaginadas: experiências educativas e construção das disposições...

com algo que permita desafiar as fronteiras que parecem conter os destinos de tantos jovens.

Recebido em maio de 2008 e aprovado em junho de 2008.

\section{Notas}

1. Trata-se de uma situação cujas raízes históricas podem ser remetidas às transformaçôes por que passou esse campo de estudos. Para uma discussão dessa questão, ver Almeida (2008).

2. Todos os nomes próprios, seja de pessoas ou localidades, foram trocados para garantir o anonimato de nossos informantes.

3. Ver também, sobre a questão, Bourdieu (1978).

4. Agradecemos a Kimi Tomizaki por nos ceder as entrevistas que realizou com os pais de Fábio.

5. Isso confirma o quanto a possibilidade de manter uma empregada doméstica sinaliza, para esse grupo social, a distância da pobreza, tal como mostra Goldstein (2003).

\section{Referências}

ALMEIDA, A.M.F. Ultrapassando o pai. In: ZAGO, N. et al. Família e escola. Petrópolis: Vozes, 2001.

ALMEIDA, A.M.F. A noção de capital cultural é útil para se pensar o Brasil? In: ZAGO, N. et al. Sociologia da educação: pesquisa e realidade. Petrópolis: Vozes, 2007.

ALMEIDA, A.M.F. O assalto dos economistas à educação. Tempo Social, São Paulo, v. 20, n. 1, p. 90-119, 2008.

ALMEIDA, W.M. Estudantes com desvantagens econômicas e educacionais e fruição da universidade. Cadernos CRH, Salvador, v. 20, n. 49, p. 35-46, 2007.

BAENINGER, R.; RODRIGUES, F. Aspectos demográficos e sociais. Campinas: NEPO/UnICAMP, s.d. (mimeo.).

BOURDIEU, P. Sociologie de l'Algérie. Paris: PUF, 1958.

BOURDIEU, P. Classement, declassement, reclassement. Actes de la Recherche en Sciences Sociales, Paris, v. 24, 1978. 
BOURDIEU, P. Futuro de classe e causalidade do provável. In: Nogueira, M.A; Catani, A. Pierre Bourdieu: escritos de educação. Petrópolis: Vozes, 1998. p. 81-126.

BOURDIEU, P; SAYAD, A. Le déracinement: la crise de l'agriculture traditionnelle en Algérie. Paris: Minuit, 1964.

CACCIAMALI, M.C. et al. Crescimento econômico e geração de emprego: consideraçóes sobre políticas públicas. Planejamento e Políticas Públicas, Brasília, DF, n. 12, p. 167-195, 1995.

COLLINS, R. Situational stratification: a micro-macro theory of inequality. Sociological Theory, Malden, MA, v. 18, n. 1, p. 17-43, 2000.

ELIAS, N. A sociedade dos individuos. Rio de Janeiro: Zahar, 1994.

GOLDSTEIN, D.M. Laughter out of place: race, class, violence, and sexuality in a Rio Shantytown. Berkeley: University of California, 2003.

GUNTHER, I.A.; GUNTHER, H. Brasílias pobres, Brasílias ricas: perspectivas de futuro entre adolescentes. Psicologia: Reflexão e Crítica, Porto Alegre, v. 11, n. 2, p. 191-207, 1998.

LAMONT, M.; MOLNÁR, V. The study of boundaries in the social sciences. Annual Review of Sociology, Palo Alto, CA, n. 28, p. 167-195, 2002.

NOBRE, E.A.C. As transformações emergentes do espaço urbano e regional do estado de São Paulo. São Paulo: FAu/USP, s.d. (mimeo.).

NOGUEIRA, M.A. A construção da excelência escolar: um estudo de trajetórias feito com estudantes universitários provenientes das camadas médias intelectualizadas. In: Nogueira, M.A.; Romanelli, G.; Zago, N. (Org.). Família \& escola: trajetórias de escolarização em camadas médias e populares. 2. ed. Petrópolis: Vozes, 2000, p. 125-154.

PEROSA, G. A aprendizagem da diferença: classe, gênero e corpo em uma escola para meninas. Cadernos Pagu, Campinas, n. 26, p. 87-111, 2006.

PORTES, É. Estratégias escolares do universitário das camadas populares: a insubordinação aos determinantes. 1993. Dissertação (Mestrado 
Fronteiras imaginadas: experiências educativas e construção das disposições...

em Educação) - Faculdade de Educação, Universidade Federal de Minas Gerais, Belo Horizonte.

REIS, E. Percepções da elite sobre pobreza e desigualdade. Revista Brasileira de Ciências Sociais, São Paulo, v. 15, n. 42, p. 143-152, 2000.

RIBEIRO, C.A.C. Estrutura de classes, condições de vida e oportunidades de mobilidade social no Brasil. In: Hasembalg, C.; Silva, N.V. Origens e destinos: desigualdades sociais ao longo da vida. Rio de Janeiro: Top Books; IUPERJ-UCAM; FAPERJ, 2003.

SABÓIA, J. A geração de emprego industrial no Brasil no quinquênio 2000/2004: um enfoque regional. Disponível em: <http:// www.redcelsofurtado.edu.mx>. Consulta em: 25 abr. 2008.

SCALON, M.C. Mobilidade social no Brasil: padrões e tendências. Rio de Janeiro: REVAN; IUPERJ-UCAM, 1999.

SEGNINI, L.R.P. Reestruturação nos bancos no Brasil: desemprego, subcontratação e intensificação do trabalho. Educação \& Sociedade, Campinas, v. 20, n. 67, p. 183-209, 1999.

TILLY, C. Social boundaries mechanisms. Philosophy of the Social Sciences, Thousand Oaks, CA, v. 34, n. 2, p. 211-236, 2004.

VIANA, M.J.B. Longevidade escolar em famílias de camadas populares: algumas condiçôes de possibilidade. 1998. Tese (Doutorado em Educação) - Faculdade de Educação, Universidade Federal de Minas Gerais, Belo Horizonte.

WACQUANT, L. Différence ethnique et différences sociales dans les écoles primaires de Nouvelle-Calédonie. Actes de la Recherche en Sciences Sociales, Paris, v. 70, n. 1, p. 47-63, 1987.

ZAGO, N. Do acesso à permanência no ensino superior: percursos de estudantes universitários de camadas populares. Revista Brasileira de Educação, São Paulo, v. 11, n. 32, p. 226-237, 2006. 